\title{
Long-surviving Anomalous Origin of the Right Pulmonary Artery from the Ascending Aorta Complicated with Pulmonary Arteriovenous Fistula
}

\author{
Rie Ueno ${ }^{1}$, Shusuke Yagi ${ }^{1}$, Masaaki Bando ${ }^{2}$ and Masataka Sata ${ }^{1}$
}

Key words: pulmonary hypertension, congenital heart disease, longest survivor

(Intern Med 58: 2749-2750, 2019)

(DOI: 10.2169/internalmedicine.2455-18)
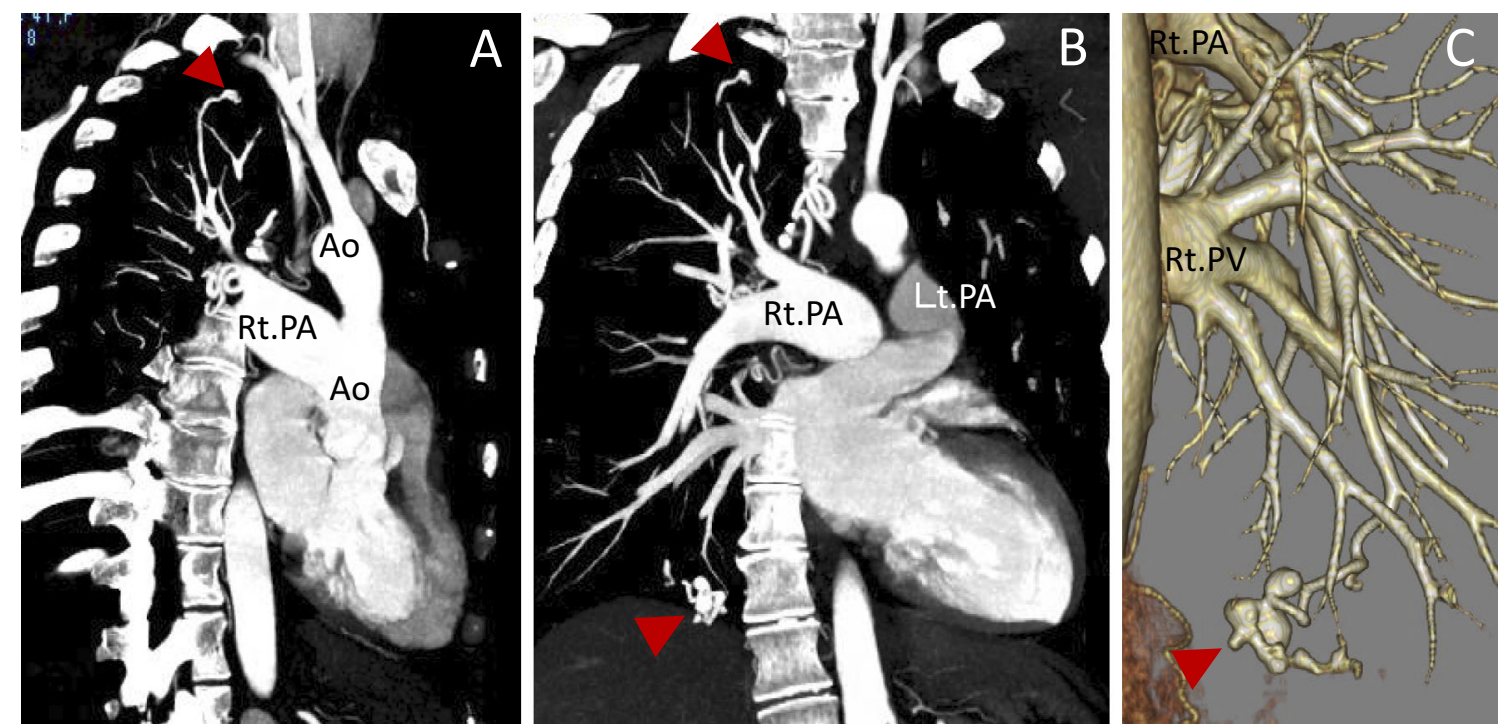

Picture.

A 41-year-old woman was referred to our hospital due to exertional dyspnea. Contrast-enhanced computed tomography (CT) showed anomalous origin of the right pulmonary artery from the ascending aorta (AORPA) and polyarteriovenous fistula in the right lung field (Picture, arrow heads). Right heart catheterization showed slight elevation of the left mean pulmonary pressure $(26 \mathrm{mmHg})$, with a normal pulmonary capillary wedge pressure $(13 \mathrm{mmHg})$. The patient elected to undergo follow-up rather than surgical repair and is no 48 years old, making her the longestsurviving uncorrected patient with AORPA recorded in the literature (1). AORPA is a rare congenital heart disease with a high mortality rate, resulting in pulmonary hypertension and heart failure without surgical repair because the right pulmonary artery is exposed to pressure overload from the systemic circulation, and the left pulmonary artery is exposed to volume overload from the systemic venous return (2). In this case, pulmonary polyarteriovenous fistula may be serving as a shunt, reducing the pulmonary arterial resistance and preventing right pulmonary arterial hypertension, leading to this patient's unusually long and ongoing survival.

${ }^{1}$ Department of Cardiovascular Medicine, Tokushima University Graduate School of Biomedical Sciences, Japan and ${ }^{2}$ Bando Heart Clinic, Japan Received: November 28, 2018; Accepted: March 11, 2019; Advance Publication by J-STAGE: June 7, 2019

Correspondence to Dr. Rie Ueno, ueno.rie@tokushima-u.ac.jp 
The authors state that they have no Conflict of Interest (COI).

\section{References}

1. Wu M, Yang G. Origin of the right pulmonary artery from the ascending aorta. Tex Heart Inst 33: 534-535, 2006.

2. Talwar S, Kothari SS, Sharma P, et al. Successful surgical correc- tion of anomalous origin of the right pulmonary artery from the aorta in an adult. J Card Surg 26: 201-204, 2011.

The Internal Medicine is an Open Access journal distributed under the Creative Commons Attribution-NonCommercial-NoDerivatives 4.0 International License. To view the details of this license, please visit (https://creativecommons.org/licenses/ by-nc-nd/4.0/).

(C) 2019 The Japanese Society of Internal Medicine Intern Med 58: 2749-2750, 2019 